\title{
TECNOLOGIA BIM: CONCEITOS, PROCESSOS DE IMPLEMENTAÇÃO E RELAÇÕES COM O PRINCÍPIO DA SUSTENTABILIDADE
}

\section{ARTIGO DE REVISÃO}

COELHO, Edilson Sousa ${ }^{1}$

COELHO, Edilson Sousa. Tecnologia BIM: Conceitos, processos de implementação e relações com o princípio da sustentabilidade. Revista Científica Multidisciplinar Núcleo do Conhecimento. Ano 05, Ed. 10, Vol. 23, pp. 114-121. Outubro de 2020. ISSN: 2448-0959, Link de acesso: https://www.nucleodoconhecimento.com.br/engenharia-civil/principio-dasustentabilidade

\section{RESUMO}

O BIM (Building Information Modeling), que em português significa Modelagem da Informação da Construção, surgiu em meados da década de 1970, a partir da publicação de um artigo científico escrito por Eastman et al. (1974). Após esse estudo, seguiu-se um notável avanço nessa área do conhecimento. Apesar disso, ainda são encontradas lacunas, especialmente, em relação aos principais conceitos dessa nova tecnologia. Assim, o objetivo desse trabalho é discorrer sobre aspectos relevantes do BIM, tais como, conceitos, processo de implementação em empresas do setor de Arquitetura, Engenharia e Construção (AEC) e as relações entre essa tecnologia e o princípio da sustentabilidade. Para tanto foi realizada uma pesquisa bibliográfica sobre o tema que fez emergir dois grandes empecilhos para o uso maciço do BIM. O primeiro

\footnotetext{
${ }^{1}$ Pós graduação em Desenvolvimento e Gerenciamento de Projetos em BIM - BIM Manager.
} 
está relacionado a questões culturais e o segundo ao aspecto financeiro das empresas.

Palavras-chave: BIM, conceitos, implementação, sustentabilidade.

\section{INTRODUÇÃO}

O Building Information Modeling - BIM melhora o processo de comunicação entre os diversos atores envolvidos em projetos de construção, fornece uma plataforma colaborativa e suporta a interoperabilidade entre os diferentes domínios de negócios. Além disso, o BIM pode aumentar tanto o desempenho como a produtividade dos negócios, se implementado com sucesso ao longo do ciclo de vida do projeto. Não obstante, a realidade dos projetos de construção impõe a interação e integração de diferentes profissionais de diversas organizações para a execução de tarefas definidas nos objetivos do projeto (AL-ASHMORI et al., 2020; OTHMAN et al., 2020). Neste sentido, visando expandir o conhecimento do assunto, esse artigo, em formato de resumo expandido, busca apresentar conceitos sobre o BIM, o processo de implementação em empresas afins, bem como sua relação com o princípio da sustentabilidade.

\section{METODOLOGIA}

A metodologia empregada para realizar a pesquisa que dá suporte ao presente artigo está baseada em uma Revisão Bibliográfica. Não obstante, o estudo foi desenvolvido por meio do viés teórico qualitativa, o qual, segundo Lüdke (2003), obriga o pesquisado a coletar dados predominantemente descritivos, seja de pessoas, situações ou fatos, ou mesmo transcrições de entrevistas e de depoimentos, assim como fotografias, desenhos e extratos de diversos modelos de documentos. Para Gil (1999) a pesquisa é um processo formal e sistemático de desenvolvimento do método científico. O objetivo fundamental da pesquisa é descobrir respostas para problemas específicos mediante o emprego de procedimentos científicos. Com efeito, a pesquisa é realizada quando se tem um problema e não se detém as informações necessárias 
para solucioná-lo. Ademais, realizou-se o levantamento, a seleção, o fichamento e o arquivamento de todas as informações relacionadas à pesquisa.

\section{RESULTADOS E DISCUSSÃO}

\section{CONCEITOS SOBRE A TECNOLOGIA BIM}

Os conceitos, as abordagens e as metodologias que hoje se identificam como BIM têm cerca de trinta anos e a terminologia "Building Information Modeling" ao menos quinze anos (EASTMAN et al., 2014). O conceito de BIM surgiu originalmente em meio a uma pesquisa publicada por Eastman et al. em 1974, a qual resultou no sistema denominado Building Description System - BDS. Resumidamente, o BDS trabalhava com quatro elementos associados: um meio para facilitar a entrada de gráficos em forma de elementos arbitrariamente complexos; uma linguagem gráfica interativa para edição e composição de arranjos de elementos; capacidades gráficas impressas que podem produzir desenhos em perspectiva ou projeções ortográficas de alta qualidade e, por fim, um recurso de classificação e formatação que permitisse a classificação da base de dados por atributos, por exemplo, tipo de material, fornecedor ou a composição de um conjunto de dados para análise (EASTMAN et al., 1974). Nos primeiros anos da década de 1980 esse conceito era comumente descrito nos Estados Unidos como "Building Product Models" (Modelos de Produtos da Construção) e na Europa, especialmente na Finlândia, como "Product Information Models" (Modelos de Informações do Produto). Com o advento de novas pesquisas esses dois termos foram substituídos por "Building Information Model" (Modelo da Informação da Construção), que por sua vez evoluiu para "Building Modeling" (Modelagem da Construção). Essa nomenclatura foi atribuída a Robert Aish, o primeiro a documentála em um artigo científico datado de 1986. Através do referido artigo estabeleceu-se os argumentos para o que hoje é conhecido como BIM e toda a tecnologia necessária para implementá-lo, incluindo modelagem 3D, extração de desenho automático, componentes inteligentes parametrizados, banco de dados relacionais e assim por diante. Posteriormente, o termo "Building Modeling" caiu em desuso e passou a se chamar "Building Information Modeling" ou Modelagem da Informação da Construção 
(EASTMAN et al., 2014). Atualmente, o BIM é tido como uma tecnologia inovadora, que representa construções em objetos geométricos 3D, intercala os objetos entre si e os integra com informações valiosas, como custo e tempo. Além disso, o modelo pode ser mantido para atualização e revisão ao longo do ciclo de vida do projeto e seu uso (AL-ASHMORI et al., 2020). Portanto, BIM é a união de pessoas, processos e tecnologia, visando um propósito específico: a modelagem da informação da construção (EASTMAN et al., 2014).

\section{O PROCESSO DE IMPLEMENTAÇÃO DO BIM}

A implementação do BIM nas empresas ligadas a indústria da Construção, deve passar necessariamente pelo crivo de sua alta administração. Ademais, sem a liderança e o envolvimento dessa ala da empresa não se pode garantir o uso otimizado do BIM (EASTMAN et al., 2014). Sua implementação requer dedicação, planejamento e, consequentemente, tempo. Envolve três elementos fundamentais de uma pessoa jurídica: tecnologia, pessoas e processos. Para cingi-los entre si utiliza-se as boas práticas consolidadas por uma empresa, bem como os procedimentos e as normas (ABDI, 2017). Há diversas finalidades de aplicação para o BIM e, por isso, sua implantação é um processo que varia conforme o perfil da empresa, com isso, os objetivos de sua implementação devem estar alinhados aos planos estratégicos da empresa (ZAGANELLI, 2020). O processo de implementação propriamente dito começa com a realização de um diagnóstico, que visa verificar as condições de qualificação dos funcionários, estrutura técnica, processos e a qualidade dos documentos gerados pela empresa (ABDI, 2017). Em seguida devem ser adotadas as demais ações para implementar o BIM, conforme Quadro 01.

Quadro 01 - Ações para implementação do BIM

\section{EMPRESA}

I. Apoio da Diretoria;

\section{PROCESSOS}

Alta ferramentas atuais;

\section{PESSOAS}

I. Definição dos requisitos de equipe; 
II. Definição da II. Medição dos resultados II. Identificação de estratégia de adoção através de indicadores usuários chave;

de acordo com o definidos;

perfil da empresa;

III. Análise de como o III. Definição de softwares e III. Programação de BIM pode agregar hardwares necessários; treinamentos;

valor a sua empresa;

IV. Definição de IV. Desenvolvimento de IV. Criação de metas claras e ferramentas para auxílio na ferramentas para a gestão objetivas; gestão do processo e do conhecimento: investimento em tutoriais, registro de customizações de software melhores práticas, lições necessárias; aprendidas,

V. Alinhamento com a V. Processo de melhoria visão organizacional. contínua e busca por otimização,

Fonte: Elaborado pelo autor com base em Zaganelli (2020)

Deve-se checar também as necessidades da empresa em relação aos aplicativos que auxiliam na condução do projeto, sistemas de armazenamento de arquivos, sistemas de controle e distribuição de arquivos internos e externos, a infraestrutura de rede, e outros aspectos inerentes à Tecnologia da Informação da empresa (ZAGANELLI, 2020). Não obstante, vale mencionar que o envolvimento dos especialistas de cada disciplina do projeto possui o condão de validar os novos processos de trabalho (MIGILINSKAS et al., 2013). Por fim, considera-se que há dois grandes empecilhos para o uso maciço do BIM nos escritórios de engenharia e arquitetura. O primeiro diz respeito a questões culturais, que impedem a migração "Instantânea" para essa nova tecnologia, ou seja, a mudança de comportamento (paradigmas) leva certo tempo para ocorrer. A outra esta relacionada a questões financeiras, pois há necessidade de realizar investimentos na aquisição de software, treinamento de pessoal, entre outros, o que representa sacrifício monetário para a empresa, que, se não houver previsão, 
pode tornar inviável a empreitada de implementação do BIM na empresa (ZAGANELLI, 2020).

\section{RELAÇÕES COM O PRINCÍPIO DA SUSTENTABILIDADE}

O conceito de Sustentabilidade esta relacionada à maneira como se deve agir em relação à natureza, de forma individual ou coletiva, para alcançar a preservação dos recursos naturais através do Desenvolvimento Sustentável, e, assim, conseguir atender as necessidades humanas presentes e futuras (KEHILY; UNDERWOOD, 2017). Diante do exposto, governos e sociedades civis organizadas estão implementando ações no sentido de construir ecocidades de baixo carbono bem como viabilizar a popularização de edifícios verdes de baixo carbono. Edifício "verde" se refere a todo o ciclo de vida de um edifício, que inclui maximizar a conservação dos recursos (energia, água, solo e materiais), proteger o meio ambiente, reduzir os diversos tipos de poluição, proporcionar às pessoas uma utilização eficiente do espaço edificado, estabelecendo uma harmonia entre natureza e arquitetura (BONENBERG; WEI, 2015). No campo de edifícios verdes e sustentáveis, o BIM pode ser utilizado para projetar edifícios alinhados ao conceito de sustentabilidade. Com o BIM é possível realizar análise do fluxo de ar e nos ecossistemas de luz solar dos edifícios. Também é possível reduzir o desperdício e melhorar a qualidade da construção. O BIM constrói uma "visualização" dos modelos digitais de construção por meio de soluções de design digital multidimensional, que fornecem a "simulação e análise" de plataformas de colaboração científica para designers, arquitetos, engenheiros de serviços públicos, desenvolvedores e até mesmo usuários finais. Além disso, o BIM auxilia na construção de modelos digitais tridimensionais de projetos desde a concepção até a construção e gestão operacional da edificação (BONENBERG; WEI, 2015).

\section{CONCLUSÕES}

Considera-se que o objetivo inicialmente traçado foi alcançado, porquanto, foram apresentados os principais conceitos relacionados ao BIM, além de expor o processo 
de sua implementação em empresas de Arquitetura, Engenharia e Construção, bem como sua relação com o conceito de Sustentabilidade.

\section{REFERÊNCIAS BIBLIOGRÁFICAS}

ABDI. GUIA 6 - A Implantação de Processos BIM. In: A Implantação de Processos BIM: Coletânea Guias BIM ABDI-MDIC. Brasília: ABDI, 2017. p. 36.

AL-ASHMORI, Y. Y. et al. Civil Engineering BIM benefits and its influence on the BIM implementation in Malaysia. Ain Shams Engineering Journal, 2020.

BONENBERG, W.; WEI, X. Green BIM in sustainable infrastructure. Procedia Manufacturing, v. 3, n. Ahfe, p. 1654-1659, 2015.

EASTMAN, C. et al. Manual de BIM: um guia de modelagem da informação da construção para arquiteto, engenheiros, gerentes, construtores e incorporadores. $1^{\text {a }}$ ed. Porto Alegre: Bookman, 2014.

EASTMAN, C.; OTHERS. An Outline of the Building Description System. Research Report No. 50. p. 23, 1974.

GIL, A. C. Métodos e Técnicas de Pesquisa Social. 5. ed. São Paulo: Atlas, 1999.

KEHILY, D.; UNDERWOOD, J. Embedding life cycle costing in 5D BIM. Journal of Information Technology in Construction, v. 22, n. August 2016, p. 145-167, 2017.

LÜDKE, M. O professor e a pesquisa. São Paulo: Papirus, 2003.

MIGILINSKAS, D. et al. The Benefits, Obstacles and Problems of Practical Bim Implementation. Procedia Engineering, v. 57, p. 767-774, 2013.

OTHMAN, I. et al. The level of Building Information Modelling (BIM) Implementation in Malaysia. Ain Shams Engineering Journal, 2020.

ZAGANELLI, D. M. TECNOLOGIA BIM E CONCEITOS. Brasília: Unyleya, 2020. 
Enviado: Outubro, 2020.

Aprovado: Outubro, 2020. 